\title{
Assessment on the Impact on Human Health, Environment, Water and Soil by Disposing Household Expired Drugs: A Cross-Sectional Study in China
}

\author{
Gehendra Mahara ${ }^{1} *$ \\ Zhihong $\mathrm{Wu}^{2, *}$ \\ Qi Gel \\ Zhiwei $\mathrm{Li}^{1}$ \\ Jinxin Zhang' \\ 'Department of Medical Statistics and \\ Epidemiology, School of Public Health, \\ Sun Yat-Sen University, Guangzhou, \\ 5 I 0080, People's Republic of China; \\ ${ }^{2}$ Research Center, Baiyunshan Hejigong \\ Pharmaceutical Factory, Guangzhou \\ Baiyunshan Pharmaceutical Holdings Co., \\ Ltd, Guangzhou, 5I 0080, People's \\ Republic of China
}

*These authors contributed equally to this work
Correspondence: Jinxin Zhang

School of Public Health, Sun Yat-Sen

University, Guangzhou, 510080, People's

Republic of China

Tel +86-20-87332453

Email zhjinx@mail.sysu.edu.cn
Background: The household expired drugs disposal has been a huge public issue in many countries, including China, which may affect various side and toxic effects on human health and environment, water resources, and soil too. This paper explores the knowledge, attitude, and practice of Guangzhou city residents regarding household expired drugs and their effect on human health and provided the scientific pieces of evidence to carry out the long-term recovery mechanism for expired medicines.

Methods: An observational, cross-sectional study was conducted using a self-structured questionnaire. Descriptive analysis, including univariate and unconditional logistic regression models, was carried out to analyze the data.

Results: A total of 613 community residents with a $99.4 \%$ response rate enrolled for the study. More than half $60.2 \%$ of residents stated that expired drugs pollute the environment, soil, and water resources, where $81.2 \%$ of respondents knew that it would produce side effects or toxic effects. However, still, $71.6 \%$ of respondents disposed of directly into the trash bin or sink, and, only $24.8 \%$ had good practice that they use a designed recycling bin. Likewise, only $8.3 \%$ of respondents placed expired drugs into collection points nearly $3-5$ times in a year, while $65.1 \%$ of participants never disposed of in the collection point, which found a worse practice.

Conclusion: Overall, the knowledge, attitude, and practice of Guangzhou residents regarding household expired drugs disposal were not ideal. To improve the resident's awareness about family expired drugs disposal, ensure the financial support for the recycling process, establish an accessible and acceptable recycling point, and introduce relevant laws and regulations for the long-term mechanism.

Keywords: household, expired drugs, knowledge, attitude, practice, collection point, Guangzhou, China

\section{Introduction}

Recent years pharmaceuticals companies have been substantially accelerating and manufacturing different pharmaceutical products globally to fulfill the population's demand for medications. This trend is predicted to extend continuously by year to year along with the population growth ${ }^{1,2}$ and at the same time families have been accumulating more spare drugs for future use in case of an emergency resulting that increasing the household expired drugs in the community. ${ }^{3}$ 
A previous study stated that about $78.6 \%$ of households preserve spare drugs at home; among them, 94.8\% of the residents mishandled those expired drugs. ${ }^{4}$ In this way, expired drugs have more prone to arise dangerous situation for their health if someone has taken unexpectedly, carelessly or mistakenly, also pollute the environment if expired drugs (household medical waste) throw out into the garbage or flushed down in the sink or the toilets. ${ }^{1}$ Unused medications have brought an increased threat, eg, childhood poisoning (accident). ${ }^{5}$ Therefore, this issue should be solved by the stockholder, organization, or government itself by making a proper rule and regulations including accessible manner for the long-term mechanism. $^{3}$

Although unavailable unified expired drugs recycling system in China, local cities or communities or state government have issued local regulations or regulatory documents for the recycling expired drugs. ${ }^{6}$ Even though, to date, residents do not know appropriately about how to deal with the expired drug. Thus, they throw away. Some countries have a particular system for the recycling, retreat, or proper handling of expired drugs. ${ }^{7-9}$ Although, the establishment of the expired drug recovery system and its long-term mechanism is still a social and debatable issue in developed as well as developing countries.

Therefore, with increasing storage of self-supplied household drugs and improper management of those drugs at home may transfer endanger to the family. Improper handling of expired drugs will pollute the environment. ${ }^{10}$ Likewise, obtaining illegal drugs through drug-dealers will cause common hidden dangers that affect the health and life of the residents. Securely disposal of family expired drugs has become a social problem. Shortterm drug recovery activities have been carried out in some parts of China since 2005. Conversely, the overall situation is not satisfactory. ${ }^{11}$

Previously conducted studies regarding the family expired drug disposal in different locations, eg, Dongcheng Districts, ${ }^{12}$ Henan Xinxiang, ${ }^{13}$ Tianjin, ${ }^{14}$ Taizhou City, ${ }^{6}$ Ruian City, in Guangdong Province, ${ }^{11}$ suggested that there is still a lack of knowledge on the treatment of expired drugs among Guangzhou residents. The investigation on attitudes and behaviors regarding the above issue has not been well investigated for the improvement of their knowledge status. Therefore, this study is aimed to conduct a study to explore the knowledge, attitude, and practice regarding household expired drugs disposal among the residents of Guangzhou City, which is the first evidence regarding family-expired drugs disposal in the study area.

\section{Methodology \\ Study Settings and Sample}

A descriptive cross-sectional study conducted in Guangzhou, China. Guangzhou, also known as Canton, the capital city of Guangdong province is the most prosperous city in South China. According to the economic development, 11 administrative districts are in Guangzhou. A convenient sampling method was used to select the participants. Considering the representativeness from urban and rural areas, four districts selected for the study, eg, Tianhe District from high economic development level, Haizhu District from medium economic development level, Liwan District and Baiyun District for the moderate economic development and suburban areas represent the city's new urban area, old city, and the suburbs (Figure 1, Table S1).

The following approach was used to calculate the sample size. The knowledge rate of the expired drug was $50 \%$, taking $\alpha=0.05, \delta= \pm 5 \%, \mathrm{p}=0.5$, and the sample size was $\mathrm{n}=384$. Allowing for the investigation error and the validity of the questionnaire when the sample size is expanded by $50 \%$, the sample size was 576 cases. The calculation formula is.

$$
n=\left(\frac{Z_{\alpha / 2} \sigma}{\delta}\right)^{2} \times p(1-p)
$$

\section{Data Collection}

The data was collected from different households and these were based on altered districts of Guangzhou city. An unanswered and unqualified questionnaires excluded before data analysis. The questionnaire was pre-tested among the participants for its validity and reliability before the final data collection (Supplementary Appendix). The project leader trained investigators uniformly. The informed consent sign was obtained from each participant after explaining the background, objective, data protection, and data privacy. After agreeing to the interview, the experienced project leaders conducted the interview. At the same time, we assured that all information was kept confidential. 


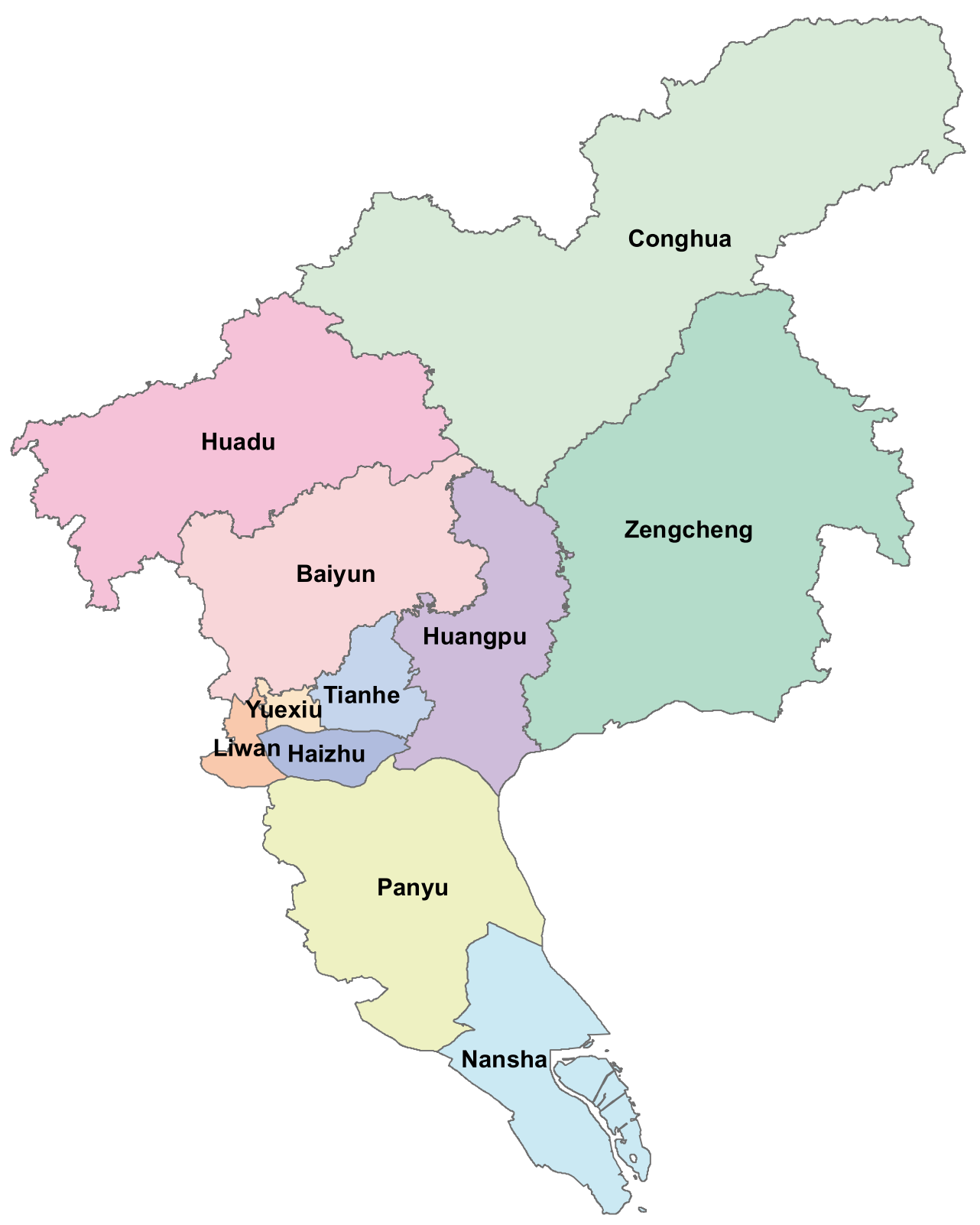

Figure I Administrative map of Guangzhou districts, China, computed by authors.

\section{Data Collection Instruments}

A standardized self-designed questionnaire (written in Chinese) was used to collect the data, where the necessary information about the knowledge, attitude, and practice of expired drugs disposal included. We need to collect the large variety of opinions from the local communities. An individual face-to-face in-depth interview (IDI) also was conducted to know the views, experiences, beliefs, and motivations regarding knowledge, attitude, and practice of expired drugs disposal. Because an indepth interview offers the opportunity to capture the views, experiences, beliefs, and motivations of descriptive information regarding the subject matter. ${ }^{15}$ This study was accompanied from February to March, 2016 with 26 general community residents in Guangzhou city, drug companies, and drug regulatory government departments (eg, six executive leaders in-charge of drug supervision in Guangdong Province and Guangzhou Municipal Food and Drug Administration, Eight pharmacy professionals from pharmacies (pharmaceutical factories), twelve community residents in Guangzhou), where, 15-25 minutes was for the interview. 
Table I Knowledge of Household Expired Drugs Disposal on Guangzhou Residents

\begin{tabular}{|c|c|c|c|}
\hline Parameter & Responses & No of Cases & Percentage (\%) \\
\hline \multirow[t]{4}{*}{ Attention towards expired date } & Always pay attention before taking each medicine all the time & 321 & 50.9 \\
\hline & Always pay attention before taking each medicine frequently & 149 & 24.3 \\
\hline & Occasionally pay attention before taking the medicine & 121 & 19.7 \\
\hline & Never pay attention before taking the medicine & 31 & 5.1 \\
\hline \multirow[t]{4}{*}{ Effective, harmful, or invalid } & Invalid, harmful & 497 & 81.1 \\
\hline & Invalid, harmless & 49 & 8 \\
\hline & Effective and harmless & 10 & 1.6 \\
\hline & Effective and harmful & 56 & 9.1 \\
\hline \multirow[t]{4}{*}{ Knowledge of cleaning up the medicine box } & Know & 89 & 14.5 \\
\hline & Know some & 298 & 48.6 \\
\hline & Do not know & 219 & 35.7 \\
\hline & No need & 7 & I.I \\
\hline \multirow[t]{4}{*}{ Hazard of expired drugs } & Pollute the environment, including soil and water resources & 369 & 60.2 \\
\hline & Cause waste of resources & 369 & 60.2 \\
\hline & Continue to take it will produce side effects & 498 & 81.2 \\
\hline & No harm & 7 & 1.1 \\
\hline \multirow[t]{4}{*}{ Efficacy of the expired drugs } & Taking will affect your health & 488 & 79.6 \\
\hline & Reduced efficacy & 92 & 15 \\
\hline & No effect & 49 & 8 \\
\hline & The drug effect remains unchanged & 4 & 0.7 \\
\hline
\end{tabular}

\section{Statistical Analysis}

After coded and decoded, all collected data are entered into the data management software Epidata 3.0. Descriptive analysis carried out and continuously, the factors affecting the knowledge, attitude, and practice of family expired drugs disposal was analyzed by single factor univariate analysis chi-square test and the unconditional logistic regression analysis. Since our study was mainly focused on the knowledge on expired drugs collecting point, and return the expired drugs to the recycling point, we only included "Do you know the expired drug collection point" (knowing that the collection point $=0$, do not know the collection point $=1$ ) as the dependent variable. Where, whether the monthly income per household was $\geq 5000$ yuan, medical insurance, expired drugs clean up knowledge, disposal via household waste products, know the adverse effect of expired drugs, the number of people having drugs every month as an independent variable for one-way chisquare and logistic regression analysis. All the statistical tests were two-sided, and the significance assumed at a 0.05 level. All analyses were performed using SPSS software version-22.
Furthermore, we analyzed qualitative data, such as verbal, record, notes and, transcription of in-depth interviews. Then, we made separate notes of each participant in MS word file according to the research question. Similarly, we applied some symbols or codes for each participant to recognize it easily, such as $01 / * 01$, etc, and categorized accordingly. We saved all respondent's information. Then, finally we summarized and combined the paragraphs and wrote the analysis report.

\section{Results}

Among 617 community residents, only 613 were valid with the response rate of $99.4 \%$, where 26 more participates were selected for an in-depth interview. Likewise, about $47 \%(\mathrm{n}=288)$ respondents had a monthly income between 2000 and 4999 Yuan (\$308-769), followed by $29.9 \%(\mathrm{n}=183)$ had 5,000 to 9999 Yuan $(\$ 769-1538)$, and $13.7 \%(\mathrm{n}=84)$ respondents had more than 10,000 Yuan (\$1539) income per month (Table S2).

Table 1 shows the knowledge about expired drugs disposal among Guangzhou residence, which was found inadequate. Only $14.5 \%(n=89)$ respondents knew about timely cleaning the medicine box, while $48.6 \%(n=289)$ 
had improper knowledge. Regarding the attention of the expiration date of drugs, $50.9 \%(n=312)$ respondents had always paid attention every time before taking medicine. Majority $81.2 \% \quad(n=498)$ of residents had reasonable knowledge that if continue taking expired drugs, then it will produce toxic effects in the body (Table 2).

Table 2 explains the influencing factors of expired drugs disposal among the respondents and results showed that district, family's monthly income, family's medical insurance, the awareness of cleaning the medicine box, family expired drugs knowledge, disposal via household waste products, expired drugs have toxic effects, and cause environmental pollution too was statistically significant (Table 2). Furthermore, unconditional logistic regression analysis results showed that knowledge about clean up the medicine box found the statistically significant $(\mathrm{OR}=0.17$, of $95 \%$ CI $0.085-0.340, \mathrm{P}=0.001$ ) influencing factor (Table S3) for expired drug disposal.

This study result showed that nearly half $47 \%(n=288)$ respondents served expired drugs to the collecting point if it is nearby home/residence, where only $25.1 \%(n=154)$ respondents stated that the distance does not matter (Table $3)$. In single-factor univariate analysis result showed that the monthly income of the family and medical insurance were statistically significant influencing factors, while in multi-factor logistic regression analysis showed that more than $>5000 ¥$ monthly income of residents $(\mathrm{OR}=2.47$, of $95 \%$ CI 1.753-3.494, $\mathrm{P}=0.001)$ and medical insurance $(\mathrm{OR}=0.59$, of $95 \% \mathrm{CI}, 0.409-0.850)$ were positive contributing factors to change the attitude of respondents towards expired drugs disposal (Tables S4 and $\underline{\mathrm{S} 5}$ ). This study identified more than half $59.7 \%(n=366)$ respondents agreed that expired drugs should be handled by the government itself, where $27.2 \%(n=167)$ believed that it is the responsibility of pharmaceuticals companies (Table 3 ).

Table 4 shows that about $31.8 \%(n=195)$ respondents always take medicine within the time of validity period; however, approximately $65.1 \%(n=399)$ indicated that they never dispose of expired drugs in collecting point resulting that majority of the respondent's $71.6 \%(n=439)$ dispose of expired drugs via household waste, while only $24.8 \%$ $(n=152)$ through expired drugs into the designated recycling bin (Table 4).

In-depth interview, more than half of the residents believed that the main reason for the expiration of the drugs at home was that respondents did not finish or take all medicines which were prescribed by doctors. About half of the respondents thought that they are requesting to the doctor for more medicines for future consumption such as cold and anti-inflammatory purpose. However, few respondents insisted that medicines expired due to a lack of proper storage place.

Additionally, most of the interviewees assumed that the reasonable way for "recycling of household expired drugs" set up, which should be located in the crowded residence place as much as possible. They also thought that it should be located in the neighborhood committee, community health service station, and near the pharmacy. Most of the respondents alleged that the recycling expenses should be borne by the government itself, where the drug administration managers $(5 / 6)$ also considered that the "family expired drug recycling work" is paid by the government, and one respondent (1/6) thought that the cost should be paid by the pharmaceutical companies. In the interview, most of the residents throw expired drugs directly into the garbage, knowing that it is harmful to the health because they did not know that expired drugs either should be recycled. The in-depth interview identified that the lack of relevant policies and regulations on expired drug disposal in the study area. Moreover, respondents emphasized more to publicity, about recycling place because they did not know where the recycling point is. The recycling practice of residents was not ideal.

\section{Discussion}

This study found that the overall knowledge about expired drugs disposal among Guangzhou residence was low such as only $14.5 \%$ of respondent timely cleaned up the medicine box, while $48.6 \%$ had still improper knowledge. A previously conducted study also stated that respondents did not frequently check out the medicine box. ${ }^{16}$ Although, to check out the expiry date of the pharmaceutical products and provide the proper guidelines about drugs before dispensed is a responsibility of all health workers and pharmacists. ${ }^{17,18}$ The present study found that $60.2 \%$ of respondents believed that expired drugs might produce environmental pollution, soil and water resource too, consistent result observed $(41.8 \%)$ in the previous study of Bound et al. ${ }^{19}$ However, awareness about the dangerous situation or fear of expired drugs effect can significantly increase via media exposure. In this study, almost $81.2 \%$ of residents had reasonable knowledge about if continuously consuming expired drugs then it will be adverse (toxic) effects in the body, almost similar finding $81.1 \%$ revealed by the earlier study 
Table 2 Influencing Factors of Household Expired Drug Disposal Knowledge in Guangzhou Residents

\begin{tabular}{|c|c|c|c|c|}
\hline \multirow[t]{2}{*}{ Variables } & \multicolumn{2}{|c|}{ No. of Cases n (\%) } & \multirow[t]{2}{*}{$x^{2}$ Value } & \multirow[t]{2}{*}{$P$-value } \\
\hline & Recycling Point & Non-Recycling Point & & \\
\hline Tianhe District & $5(3.6)$ & $135(96.4)$ & \multirow[t]{4}{*}{64.574} & \multirow[t]{4}{*}{$<0.0001$} \\
\hline Haizhu District & $31(23.1)$ & $103(76.9)$ & & \\
\hline Baiyun District & $6(8.0)$ & $69(92.0)$ & & \\
\hline Liwan District & $87(36.1)$ & $54(63.9)$ & & \\
\hline \multicolumn{5}{|l|}{ Monthly income of the family (yuan) } \\
\hline$<2000$ Yuan $(\$ 07.8)$ & $16(29.1)$ & $39(70.9)$ & 8.135 & 0.043 \\
\hline $2000 \sim 4999(\$ 308-769.4)$ & $68(24.7)$ & $207(75.3)$ & & \\
\hline $5000 \sim 9999$ (\$769-1538.9) & $35(19.8)$ & $142(80.2)$ & & \\
\hline$>10000(\$ 1539.1)$ & $10(12.0)$ & $73(88.0)$ & & \\
\hline \multicolumn{5}{|l|}{ Family members: } \\
\hline$\leq 3$ & $55(20.7)$ & $211(79.3)$ & 0.400 & 0.527 \\
\hline$>3$ & $74(22.8)$ & $250(77.2)$ & & \\
\hline \multicolumn{5}{|l|}{ Whether the family take medicine every month: } \\
\hline Yes & $2(23.4)$ & $95(76.6)$ & 0.213 & 0.627 \\
\hline No & $100(21.5)$ & $366(78.5)$ & & \\
\hline \multicolumn{5}{|l|}{ Covered by medical insurance } \\
\hline Yes & $98(24.3)$ & $306(75.7)$ & 4.296 & 0.042 \\
\hline No & $31(16.7)$ & $155(83.3)$ & & \\
\hline \multicolumn{5}{|l|}{ Expired drugs Clean-up knowledge: } \\
\hline Know & $42(47.7)$ & $46(52.3)$ & 60.472 & $<0.0001$ \\
\hline Know some & $69(24.6)$ & $211(75.4)$ & & \\
\hline Do not know & $17(7.9)$ & $198(92.1)$ & & \\
\hline No need & I (14.3) & $6(85.7)$ & & \\
\hline \multicolumn{5}{|l|}{ Do you know the collection point?: } \\
\hline Yes & $129(35.2)$ & $237(64.8)$ & 101.043 & $<0.0001$ \\
\hline No & $0(0)$ & $224(100)$ & & \\
\hline \multicolumn{5}{|l|}{ Dispose via household waste products: } \\
\hline Yes & $61(17.3)$ & $292(82.7)$ & 10.809 & 0.001 \\
\hline No & $68(28.7)$ & $169(71.3)$ & & \\
\hline \multicolumn{5}{|l|}{ Knowledge about its side effects: } \\
\hline Yes & $83(17.3)$ & $396(82.7)$ & 30.672 & $<0.0001$ \\
\hline No & $46(41.4)$ & $65(58.6)$ & & \\
\hline \multicolumn{5}{|l|}{ Knowledge about polluting the environment: } \\
\hline Yes & $87(24.7)$ & $265(75.3)$ & 4.153 & 0.043 \\
\hline No & $42(17.6)$ & $196(82.4)$ & & \\
\hline \multicolumn{5}{|l|}{ Effectiveness/Harmfulness of Expired drugs } \\
\hline Invalid and Harmful & $106(22.2)$ & $372(77.8)$ & 4.733 & 0.192 \\
\hline Ineffective & $12(25.0)$ & $36(75.0)$ & & \\
\hline Effective and harmless & $4(40.0)$ & $6(60.0)$ & & \\
\hline Effectively harmful & $7(13.0)$ & $47(87.0)$ & & \\
\hline
\end{tabular}


Table 3 Attitudes of Guangzhou Residents on Family Expired Drugs

\begin{tabular}{|c|c|c|c|}
\hline Variables & Responses & $\begin{array}{l}\text { No of } \\
\text { Cases }\end{array}$ & Percentage (\%) \\
\hline $\begin{array}{l}\text { Attitude towards Collection point distance and } \\
\text { delivery }\end{array}$ & $\begin{array}{l}\text { No matter how far away from home } \\
\text { If collection point is too far from home, you will not be } \\
\text { served } \\
\text { If it is close to home, it will be served } \\
\text { Will not serve }\end{array}$ & $\begin{array}{l}154 \\
127 \\
288 \\
44\end{array}$ & $\begin{array}{l}25.1 \\
20.7 \\
47 \\
7.2\end{array}$ \\
\hline Attitude to encouraging measures & $\begin{array}{l}\text { Issue a drug discount card } \\
\text { Give a small gift } \\
\text { Safety medication booklet } \\
\text { Other incentives }\end{array}$ & $\begin{array}{l}287 \\
154 \\
170 \\
47\end{array}$ & $\begin{array}{c}46.8 \\
25.1 \\
27.7 \\
7.7\end{array}$ \\
\hline $\begin{array}{l}\text { Attitude of the recycling methods of expired } \\
\text { drugs }\end{array}$ & $\begin{array}{l}\text { In recycling box according to hazard nature } \\
\text { Designed recycle point or Recycle Bin } \\
\text { Personal visit and recycling the garbage } \\
\text { Sent back to the factory and replaced by new }\end{array}$ & $\begin{array}{l}166 \\
343 \\
75 \\
68\end{array}$ & $\begin{array}{c}27.1 \\
56 \\
12.2 \\
11.1\end{array}$ \\
\hline Attitude of Recycling point setting & $\begin{array}{l}\text { Community health station } \\
\text { Neighborhood committee } \\
\text { Pharmacy } \\
\text { Other }\end{array}$ & $\begin{array}{c}214 \\
173 \\
256 \\
20\end{array}$ & $\begin{array}{c}34.9 \\
28.2 \\
41.8 \\
3.3\end{array}$ \\
\hline Attitude of Recycling funds bear department & $\begin{array}{l}\text { Government } \\
\text { Pharmaceutical companies } \\
\text { Pharmacy } \\
\text { Does not matter }\end{array}$ & $\begin{array}{l}366 \\
167 \\
38 \\
66\end{array}$ & $\begin{array}{c}59.7 \\
27.2 \\
6.2 \\
10.8\end{array}$ \\
\hline Effectiveness of recycling measures & $\begin{array}{l}\text { National legislation becomes a social responsibility and } \\
\text { obligation } \\
\text { Material encouragement } \\
\text { Strengthen publicity and guidance } \\
\text { Set up as many collection points as possible } \\
\text { Trade-in old for new }\end{array}$ & $\begin{array}{l}254 \\
251 \\
360 \\
351 \\
266\end{array}$ & $\begin{array}{l}41.4 \\
40.9 \\
58.7 \\
57.3 \\
43.4\end{array}$ \\
\hline Views on recycling work & $\begin{array}{l}\text { Introduce relevant policies to avoid pollution } \\
\text { Introduce relevant policies to avoid waste } \\
\text { Self-addressed according to individual circumstances } \\
\text { No need }\end{array}$ & $\begin{array}{c}351 \\
248 \\
73 \\
10\end{array}$ & $\begin{array}{c}57.3 \\
40.5 \\
11.9 \\
1.6\end{array}$ \\
\hline
\end{tabular}

of Bound et $\mathrm{al}^{20}$ and this finding also supports by the study of Bhayana et al. ${ }^{21}$

This study found that family's monthly income, family's medical insurance coverage, the awareness of cleaning the medicine box, expired drugs produce toxic effects and pollute environment, statistically were significant influencing factors of knowledge regarding expired drug disposal. The expired drugs clean-up knowledge was positively associated with knowledge of respondents, which considered that "knowing the knowledge of expiring drug cleanup" tends to be close to put the family expired drug at the collection point. Therefore, it has been considered that the in-depth promotion of family expired drugs cleaning knowledge is a contributing factor to the recovery of family expired drugs.

An essential and the significant debatable issue regarding who is responsible for collecting and recycling of expired drugs, in this regard, about $59.7 \%$ of respondent agreed that it should be handed by the government itself, where $27.2 \%$ supposed that it is the responsibility of pharmaceuticals companies. However, the primary responsibility of disposing of expired drugs should be a task of the government itself with an appropriate rule, regulations, and policy revealed by $^{22}$ Al-Shareef et al, which is somehow applying in the Chinese community too. This present study found that $11.1 \%$ of respondent returned expired drugs to factory or 
Table 4 Practice of Expired Drugs Disposal by Guangzhou City Residents

\begin{tabular}{|c|c|c|c|}
\hline Variables & Responses & $\begin{array}{l}\text { No. of } \\
\text { Cases }\end{array}$ & $\begin{array}{l}\text { Percentage } \\
\text { (\%) }\end{array}$ \\
\hline \multirow[t]{4}{*}{ Whether to take the drug in order of the validity } & Always & 195 & 31.8 \\
\hline & Often & 173 & 28.2 \\
\hline & Occasionally & 155 & 25.3 \\
\hline & Never & 90 & 14.7 \\
\hline \multirow{4}{*}{$\begin{array}{l}\text { Frequency of expired drugs dispose into the collection point in } \\
\text { a year }\end{array}$} & Always (5 times or more) & 22 & 3.6 \\
\hline & Often ( $3-5$ times $)$ & 51 & 8.3 \\
\hline & Occasionally ( $1-2$ times) & 141 & 23 \\
\hline & Never & 399 & 65.1 \\
\hline \multirow[t]{4}{*}{ Frequency of expired drugs cleaning up } & Always cleaning up (I-2 months) & 65 & 10.6 \\
\hline & Frequently cleaning up (3-6 months) & 166 & 27.1 \\
\hline & Occasionally cleaning up (7-12 months) & 317 & 51.7 \\
\hline & Never cleaning up (more than 12 months) & 65 & 10.6 \\
\hline \multirow[t]{4}{*}{ Cleaning-up expired drugs } & $\begin{array}{l}\text { Put it into the designated recycling bin or } \\
\text { collection point }\end{array}$ & & 24.8 \\
\hline & Throw it away as trash & 439 & 71.6 \\
\hline & $\begin{array}{l}\text { Reluctant to throw it away, continue to store or } \\
\text { take }\end{array}$ & 12 & 2 \\
\hline & Other treatment methods & 10 & 1.6 \\
\hline \multirow[t]{5}{*}{ Type of drugs stored } & 0 types & 20 & 3.3 \\
\hline & I-3 types & 139 & 22.7 \\
\hline & 4-6 types & 230 & 37.5 \\
\hline & $7-10$ types & 109 & 17.8 \\
\hline & More than 10 types & 115 & 18.8 \\
\hline \multirow[t]{4}{*}{ Frequency of reserving drugs } & Always reserving drugs & 244 & 39.8 \\
\hline & Frequently reserving drugs & 183 & 29.9 \\
\hline & Occasionally reserving small amounts of drugs & 177 & 28.9 \\
\hline & No drugs reserved & 9 & 1.5 \\
\hline \multirow[t]{6}{*}{ Type of the drugs reserved } & Drugs for common diseases & 500 & 81.6 \\
\hline & Drugs for external use & 398 & 64.9 \\
\hline & Drugs for health protection & 161 & 23.6 \\
\hline & Drugs for first-aid & 198 & 32.3 \\
\hline & Drugs for chronic disease & 154 & 25.1 \\
\hline & Other drugs & 9 & 1.5 \\
\hline
\end{tabular}

pharmacy and replaced by the new one, where only $10 \%$ returned to the Central Drug Store in Kuwait, ${ }^{23}$ indicating that Guangzhou residence had a quite right attitude compared with previous studies of Al-Shareef et al. ${ }^{22}$ Tong et al, ${ }^{25}$ indicated that only $1.4 \%$ and $2 \%$ of respondents returned expired drugs to a pharmacy in the USA and Saudi Arabia. Expired drugs "take-back" and "mailbag" programs have well known in several countries where pharmacies and pharmacists have substantial roles in the collection and recycling process. ${ }^{5,23}$ However, so far, this facility is not well-practiced in China.
This study found that majority of the respondent's $71.6 \%$ dispose of expired drugs via household waste, which tendency is quite similar $79.1 \%$ with the previous study of Fatma Al-Shareef et al, ${ }^{22}$ conducted in Saudi Arabia, and $87 \%$ in the USA. Likewise, direct throwing into trash or bin has identified as the most common means of disposal way in many countries, eg, the USA, the UK, Serbia, Kuwait, ${ }^{23}$ Saudi Arabia, Pakistan, India. ${ }^{2,20,22,23,25}$ Additionally, the next commonly used method for expired drugs is identified as flushing down into the toilet or sink directly. $^{25}$ The potential disparities regarding disposal of 
expired drugs vary according to demographic characteristics, health-seeking behavior, and existing law and legislation of that particular state. ${ }^{26}$

Likewise, this study found several issues, such as relevant policies and programs of expired drugs, insufficient publicity of recycling point, low number of collection points, weak awareness about the recycling process, and low enthusiasm to recycle it. Fewer studies regarding expired drugs disposal and the cost of the recycling process, which is too high are the main lacking factors of disposal and recycling household expired drugs in Guangzhou city. To solve these issues, the government itself, stockholders, and other organizations as well as the health community needed to make a co-operation and look forward to a long-term solution. A previous study also suggested that the government should make a proper design a subsidy policy to return and recycle expired drugs and establish proper expired drugs collection points in the community. ${ }^{3}$

Expired drugs are different from regular garbage. There was no such system to provide compensation for expired drugs. At present, the recycling of expired drugs in China has not been supported by the State Government. The pharmaceutical companies in China have borne the cost of expired drug recycling. The ongoing work has been facing significant economic burdens. ${ }^{27}$ Due to the relatively high economic pressure on the harmless destruction of expired drugs, about $90 \%$ of pharmaceutical companies have not recycled expired household drugs. The large company, eg, GPHL, has been recycling expired drugs, even though they find it is difficult to maintain such high destruction costs, which may become a bottleneck restricting their continued public welfare. ${ }^{28}$

The strength of this study is that results provide essential information for the next planning and improving health education intervention and mass media campaign to improve the KAP of Guangzhou residents. Despite that, this study has some limitations. First, this is a crosssectional study design, which limits the generalizability of the findings. Second, we obtained the information using a self-structured questionnaire; therefore, the responses of participants were prone to be information bias.

\section{Conclusion}

The awareness regarding household expired drugs disposal of Guangzhou residents was relatively low. The most common method of household expired drugs disposal was through trash or bin via household waste products because most of the respondents did not know the collecting/recycling point. Such knowledge, attitude, and practice stand possible threats to the population which needed to be solved. Their collection point or recycling point should be disseminated via mass media exposure alongside the legislation, policies, and programs and applied subsequently to make such changes towards expired drugs disposal. Further brief educational interventions should be carried out to improve the resident's knowledge, attitude, and practice regarding expired drugs disposal.

\section{Recommendation}

As per our study findings, and knowledge, we have made the following recommendations:

1. The best way to dispose of expired or unused drugs is to drop off in the expired drugs collection center.

2. If there is no such facility for collection counter nearby then immediately flush this potentially dangerous medicine into the toilet (only flushable list items).

3. There are few drugs that cannot be flush, such medicines can result in death from even a single dose if it has taken inappropriately.

4. Always keep safe those drugs from children, adults, or pet in the home, that can accidentally or intentionally ingest, touch, misuse, or abuse and can be dangerous for everyone's life.

5. Review the instructions of the medicines or prescription of doctor or contact to health professional such as a pharmacist, doctor to find out the proper way to dispose expired medicines.

6. Read the specific instructions carefully for sprays, lozenges, ointment, and inhaler to discard into the trash at home, and if possible then check with the nearest pharmacist about collection center and disposal system.

7. Check with the community health center or health care management team of the local community or hospital about how, where, and what is the best way to dispose of the expired drugs.

8. Start awareness champion about drug take-back program, flushing medicines, disposable medicines in household trash, flushing drugs, and environmental pollution, etc by advertising media, poster, pamphlet, health education to the community. 
9. Make a healthy public policy regarding expired drug disposal and promote it to utilize properly.

\section{Ethical Approval}

This study was conducted in accordance with the Declaration of Helsinki. Ethical approval had been approved by the Ethics Committee of the School of Public Health, Sun Yat-Sen University, Guangzhou, China. The ethical approval number is $053-2018$. The written and verbal sign was taken with each respondent in an informed consent form at the beginning of each survey.

\section{Acknowledgment}

The authors thank the Ministry of Science and Technology, National Natural Science Foundation of China and, Natural Science Foundation of Guangdong Province, China, China for providing us with the fund support for this study. Moreover, we thank our colleagues Tuoheti Reheman, Chaolun Li, Zichao Liang, Siyang Chen, Leen Huang at the Department of Epidemiology and Health Statistics, School of Public Health, Capital Medical University, for their valuable suggestions and software support.

\section{Author Contributions}

All authors made a significant contribution to the work reported, whether that is in the conception, study design, execution, acquisition of data, analysis and interpretation, or in all these areas; took part in drafting, revising or critically reviewing the article; gave final approval of the version to be published; have agreed on the journal to which the article has been submitted; and agree to be accountable for all aspects of the work.

\section{Funding}

This work was supported by the National Natural Science Foundation of China (NSFC, 81773545); and the Natural Science Foundation of Guangdong Province, China (2016A030313365). The funders had no role in study design, data collection, and analysis, decision to publish, or preparation of the manuscript.

\section{Disclosure}

The authors report no conflicts of interest in this work.

\section{References}

1. Barnett-Itzhaki Z, Berman T, Grotto I, Schwartzberg E. Household medical waste disposal policy in Israel. Isr J Health Policy Res. 2016:5. doi:10.1186/s13584-016-0108-1

2. Kusturica MP, Sabo A, Tomic Z, Horvat O, Šolak Z. Storage and disposal of unused medications: knowledge, behavior, and attitudes among Serbian people. Int J Clin Pharm. 2012;34(4):604-610. doi:10.1007/s11096-012-9652-0

3. Huang H, Li Y, Huang B, Pi X. An optimization model for expired drug recycling logistics networks and government subsidy policy design based on tri-level programming. Int $J$ Environ Res Public Health. 2015;12(7):7738-7751. doi:10.3390/ijerph120707738

4. Ma L, Ma A. Discussion on the establishment of China's drug recycling system. Pharm Forum. 2006;15(15):16.

5. Braund R, Peake BM, Shieffelbien L. Disposal practices for unused medications in New Zealand. Environ Int. 2009;35(6):952-955. doi:10.1016/j.envint.2009.04.003

6. Li X. Research on the status quo and countermeasures of expired drug recycling in Taizhou. Zhejiang Univ Technol. 2009.

7. Zhou H. The basic concept of Swedish public health system. Chin Public Health Manag. 2008;24(2):221-223.

8. Mao J. How to deal with drug waste in France. Contempor Med. 2006;13(5):76.

9. Liu S, Yu T. Comparison of Chinese and foreign drug recycling models. Logist Engineer Manag. 2009;31(2):99-101.

10. Law of the People's Republic of China. Drug control law of the People's Republic of China. Available from: http://www.npc.gov.cn/ englishnpc/Law/2007-12/13/content_1383969.htm. Accessed October 22, 2018.

11. Xia F, Zhang L, Li H, et al. Knowledge, attitude and behavior investigation of expired drug recycling in Guangdong residents. Chin Med Guide. 2013;11(19):770-772.

12. Wang W, Sun J, Kiu S. Suggestions on the treatment of expired drugs. China Pharm. 2009;18(6):7.

13. Yuan C, Zhao Y, Li B. Investigation on the status quo of expired drug disposal in rural households in Xinxiang, Zhengzhou, Henan Province. Chin Pharm Affairs. 2014;28(9):972-976.

14. Qin Y, Li D, Zhang F. Current status and countermeasures of family expired drug disposal in Tianjin. $J$ Tianjin Univ Trad Chin Med. 2013;32(2):113-115.

15. Ranney ML, Meisel Z, Choo EK, Garro A, Sasson C, Morrow K. Interview-based qualitative research in emergency care part II: data collection, analysis and results reporting. Acad Emerg Med. 2015;22 (9):1103-1112. doi:10.1111/acem.12735

16. Akici A, Aydin V, Kiroglu A. Assessment of the association between drug disposal practices and drug use and storage behaviors. Saudi Pharm J. 2018;26(1):7-13. doi:10.1016/j.jsps.2017.11.006

17. World Health Organization. Guidelines for the safe disposal of expired drugs; 2018. Avaialble from: http://www.emro.who.int/ images/stories/pakistan/documents/pak_documents/Guidelines_for_ Expired_Medicines.pdf. Accessed October 18, 2018.

18. U.S. Food \& Drugs Administration. Safe disposal of medicines disposal of unused medicines: what you should know; 2018. Available from: https://www.fda.gov/Drugs/ResourcesForYou/ Consumers/B u y ing Using Medicine S a f e ly/ EnsuringSafeUseofMedicine/SafeDisposalofMedicines/ucm 186187. htm. Accessed October 22, 2018.

19. Bound JP, Kitsou K, Voulvoulis N. Household disposal of pharmaceuticals and perception of risk to the environment. Environ Toxicol Pharmacol. 2006;21(3):301-307. doi:10.1016/j.etap.2005.09.006

20. Bound J, Voulvoulis N. Household disposal of pharmaceuticals as a pathway for aquatic contamination in the United kingdom. Environ Health Perspect. 2005;113(12):1705-1711. doi:10.1289/ehp.8315 
21. Bhayana K, Rehan HS, Arora T. Comparison of the knowledge, attitude, and practices of doctors, nurses, and pharmacists regarding the use of expired and disposal of unused medicines in Delhi. Indian J Pharmacol. 2016;48(6):725-728. doi:10.4103/0253-7613.194846

22. Al-Shareef F, El-Asrar SA, Al-Bakr L, et al. Investigating the disposal of expired and unused medication in Riyadh, Saudi Arabia: a cross-sectional study. Int J Clin Pharm. 2016;38(4):822-828. doi:10.1007/s11096-016-0287-4

23. Abahussain E, Waheedi M, Koshy S. Practice, awareness and opinion of pharmacists toward disposal of unwanted medications in Kuwait Saudi Pharm J. 2012;20(3):195-201. doi:10.1016/j.jsps.2012.04.001

24. Glassmeyer S, Hinchey E, Boehme S, et al. Disposal practices for unwanted residential medications in the United States. Environ Int. 2009;35(3):566-572. doi:10.1016/j.envint.2008.10.007
25. Tong AYC, Peake BM, Braund R. Disposal practices for unused medications around the world. Environ Int. 2011;37(1):292-298. doi:10.1016/j.envint.2010.10.002

26. Kusturica MP, Tomas A, Tomic Z, et al. Analysis of expired medications in Serbian households. Slovenian J Public Health. 2016;55 (3):195-201. doi:10.1515/sjph-2016-0025

27. Chen Y. On the institutionalization and related problems of family expired drug recovery mechanism. Chin Food Drug Admin. 2009;7 (8):64-66.

28. Wang Y, Wu B, Sheng R. Legislation of expired drug recycling is imperative. Chin Pharm Affairs. 2007;21(6):377-380.
Risk Management and Healthcare Policy

\section{Publish your work in this journal}

Risk Management and Healthcare Policy is an international, peerreviewed, open access journal focusing on all aspects of public health, policy, and preventative measures to promote good health and improve morbidity and mortality in the population. The journa welcomes submitted papers covering original research, basic science, clinical \& epidemiological studies, reviews and evaluations,

\section{Dovepress}

guidelines, expert opinion and commentary, case reports and extended reports. The manuscript management system is completely online and includes a very quick and fair peer-review system, which is all easy to use. Visit http://www.dovepress.com/testimonials.php to read real quotes from published authors.

Submit your manuscript here: https://www.dovepress.com/risk-management-and-healthcare-policy-journal 